\title{
Telenovela \\ Projeção, identidade e identificação \\ na modernidade líquida
}

\author{
Aline Silva Correa Maia ${ }^{1}$ \\ Universidade Federal de Juiz de Fora
}

\begin{abstract}
Resumo: A partir da relação personagem de novela $x$ sociedade, pretendemos evidenciar o papel dos meios de comunicação, especificamente da televisão, na configuração dos indivíduos e, por extensão, das estruturas sociais. Uma vez que as relações entre sujeitos são cada vez mais mediadas, percebemos a importância em apontar como um personagem ficcional é capaz de formar opiniões, ditar comportamentos e reforçar papéis sociais. A fim de compreender a produção de sentidos impetrada pelas figuras dramáticas construídas para e na TV, empreenderemos breve revisão bibliográfica de autores que analisam questões referentes às identidades no período de modernidade líquida, assim como analisaremos, particularmente, a simpatia e a identificação provocadas no público pela personagem interpretada por Camila Pitanga na novela Paraíso Tropical, exibida pela TV Globo.
\end{abstract}

Palavras-chave: Identidade. Personagem. Telenovela

\begin{abstract}
From the soap opera character $x$ society relationship, it is intended to highlight the media role - specifically the TV role - in the configuration of individuals and, as an extension, of social structures. Since the relationships between subjects are more and more mediated, it has been noticed that it is important to point how a fictional character can form opinions, impose behaviours and reinforce social roles. In order to understand the values produced by the characters built for and on TV, a brief bibliographical review is undertaken on authors who analyze issues on identities in modernity. A particular analysis on the identification with spectators of the role played by Camila Pitanga in the "Paraíso Tropical" soap opera in TV Globo is carried out, as well.
\end{abstract}

Key words: Identity. Character. Soap opera.

1 Jornalista graduada na Faculdade de Comunicação da Universidade Federal de Juiz de Fora - UFJF; mestranda em Comunicação e Sociedade do PPGCom-UFJF; produtora TV Panorama - afiliada Rede Globo. Desenvolve pesquisas na linha de Comunicação e Identidades 
Resumen: De la relación de la sociedad x personaje de telenovela, se piensa para destacar el papel de los medios - específicamente el papel de la TV - en la configuración de individuos y, como extensión, de estructuras sociales. Puesto que las relaciones entre los individuos se median cada vez más, se ha notado que es importante señalar cómo un personaje puede formar opiniones, impone comportamientos y refuerza papeles sociales. Para entender los valores produjo por los caracteres construidos para y en la TV, una breve revisión bibliográfica se emprende en los autores que analizan ediciones en identidades en modernidad. Un análisis particular en la identificación con los espectadores del actuado en papel por Camila Pitanga en la telenovela "Paraíso tropical" en TV Globo se realiza, también.

Palabras clave: Identidad. Personaje. Telenovela.

Résumé: Du rapport de société $X$ feuilleton televise du caractère, on le prévoit pour accentuer le rôle de médias - spécifiquement le rôle de TV-dans la configuration des individus et, comme prolongation, des structures sociales. Puisque les rapports entre les sujets de plus en plus sont négociés, on l'a noté qu'il est important de diriger comment un caractère fictif peut former des avis, impose des comportements et renforce des rôles sociaux. Afin de comprendre les valeurs produites par les caractères établis pour et sur la TV, une brève revue bibliographique est entreprise sur les auteurs qui analysent des questions sur des identités dans la modernité. Une analyse particulière sur l'identification avec des spectateurs du joué un rôle par Camila Pitanga dans feuilleton télévisé de "Paraíso Tropical" dans TV Globo est effectuée, aussi bien.

Mots clés: Identité. Caractère. Feuilleton télévisé.

\section{Introdução}

A queda de conceitos até então rígidos e que serviam de base para a delimitação das identidades (re)conhecidas - raça, gênero, classe, etc - colabora para a percepção de outras categorias identitárias como, por exemplo, aquelas advindas da orientação sexual e da localidade geopolítica. Processos históricos estão entrando em colapso e novas identidades estão sendo forjadas. Desponta uma reconfiguração social em que a existência do indivíduo é marcada por um "estar na fronteira", em constante busca de localização temporal e espacial. Enquanto a pessoa humana perde as características de individualidade, os meios de comunicação de massa consolidamse como vitrines que servem a fins de composição identitária. 
Vivemos na modernidade líquida marcada pelo encurtamento das distâncias físicas, valorização do poder de consumo e presença acentuada da mídia nas relações sociais. Em nossas casas, nos dividimos entre as tarefas cotidianas e a parada na frente da televisão para acompanhar mais um capítulo da "novela das oito". Reunidos na sala, ou cada qual em seu quarto, somos bombardeados por representações contidas em mensagens de entretenimento ou mesmo publicitárias. Recorrendo a idéias e valores presentes no imaginário popular, a televisão apresenta figuras que logo são oficializadas em modelos de pronta identificação e visibilidade.

Potente difusora de imagens, a televisão interfere no cotidiano do receptor na medida em que "produz determinados tipos de identidade - por exemplo, por meio da narrativa das telenovelas, dos anúncios e das técnicas de venda" (WOODWARD, 2000, 30), colocando na mesa dos brasileiros, de segunda a segundafeira, informações orientadas que poderão ser consumidas a bel prazer por quem as desejar.

A influência da televisão no Brasil é visível nas ruas onde é possível identificar mulheres, por exemplo, desfilando com calças semelhantes às utilizadas no dia anterior por uma personagem de novela. Ou, ainda, não raro ouvimos em rodas de conversa o debate fervoroso sobre tema lançado no último capítulo do folhetim das sete. Percebemos nas telenovelas uma estrutura formal determinante de sentidos e que cada vez mais ganha visibilidade como agente dinamizador de construções identitárias.

Diante de um personagem de novela, o indivíduo pode ou não se projetar, desencadeando convergência de desejos ou mesmo partilha de interesses, de forma que num processo de simpatia / empatia com a imagem a-presentada poderá identificar-se, e até chegar ao ponto de anular-se, passando a reconhecer-se enquanto a própria figura da TV. E é a partir da relação personagem de novela versus sociedade, que pretendemos, neste artigo, apontar o papel dos meios de comunicação, especificamente da televisão, na configuração dos indivíduos e, por extensão, das estruturas sociais.

Para exemplificar esta reflexão, examinaremos a personagem Bebel, uma garota de programa, interpretada pela atriz Camila Pitanga, na novela Paraíso 
Tropical, exibida desde março de 2007, no horário de 21 horas pela Rede Globo. Se em nossa sociedade as relações entre sujeitos são cada vez mais mediadas, percebemos a importância em apontar como um personagem, ainda que em um produto ficcional, é capaz de formar opiniões, ditar comportamentos e reforçar papéis sociais.

A fim de compreender a produção de sentidos impetrada pelas figuras dramáticas construídas para e na TV, empreenderemos breve revisão bibliográfica de autores que analisam questões referentes às identidades na atualidade, bem como abordaremos o cinema como precursor da televisão e abre-alas para a contemplação de imagens e conceitos inspiradores de criações sociais e culturais.

\section{Identidades líquidas ... e no liquidificador}

Na modernidade líquida apresentada por Bauman (2005), a decadência de instituições sociais que até então se prestavam como referência para a construção da sociedade provoca o que Stuart Hall (2006) intitula de crise da identidade. Paisagens culturais de classe, gênero e etnia que no passado forneciam os alicerces para a localização dos indivíduos estão sendo fragmentadas.

A identidade do sujeito pós-moderno já não é taxada como fixa ou permanente, como acontecia no Iluminismo. Passa-se a compreender que o indivíduo pode assumir diferentes posições, conforme o papel que está representando, gerando um processo de identificação que não é automático, mas pode ser ganho ou perdido ao longo de sua trajetória. A complexidade da vida cotidiana, atravessada pela globalização que encurta distâncias e conecta comunidades em novas estruturas de espaço-tempo, impõe que assumamos distintas identidades que podem ser conflitantes entre si. Posicionamo-nos frente ao outro de acordo com as expectativas lançadas sobre nós.

Conciliar identidades pode não ser uma tarefa fácil, de maneira que estaremos sempre deslocados, ou seja, não estamos totalmente em lugar algum, o que nos coloca na situação de sempre precisarmos dar explicações, por um lado, ou mesmo estarmos em constante negociação, por outro. Nossa localização é contínua em uma região de barganha, de troca, de maneira a influenciar nas identidades, que 
por rua vez tornam-se flutuantes, líquidas, assim como nosso tempo, conforme sugere Bauman.

Neste período em que nova roupagem é dada às identidades, estas não devem ser incorporadas com "unhas e dentes”, como verdade única. Mas é preciso estar pronto para abandonar uma posição e tão logo assumir outra. Na era líquidomoderna, as relações humanas tendem também a se tornar voláteis, descartáveis, substituíveis como um tênis comprado há poucos meses e que perde lugar para um modelo mais novo, mesmo estando ainda em condições de uso. Assim, o amor, por exemplo, é reduzido ao modo consumista de ser e de viver, sendo descartado quando perde seus atrativos iniciais. Da mesma forma que as identidades, as relações amorosas tornaram-se efêmeras, líquidas, rapidamente esgotam-se e são abandonadas por outras mais convenientes aos olhos dos indivíduos que as almejam. O comprometimento e o compromisso em longo prazo são vistos como armadilhas a serem evitadas.

O futuro sempre foi incerto, mas o seu caráter inconstante e volátil nunca pareceu tão inextricável como no líquido mundo moderno da força de trabalho flexível, dos frágeis vínculos entre os seres humanos, dos humores fluidos, das ameaças flutuantes e do incontrolável cortejo de perigos camaleônicos (BAUMAN, 2005, 74).

Homi Bhabha (2005) também confere ao descentramento do sujeito a percepção de outras categorias estabelecidos e fixos. Neste ambiente de não lugar - já que estão ausentes referências e eixo imóvel para os indivíduos - identidade torna-se um conceito sob rasura, como sugere Hall; ou seja, uma palavra cortada, mas que pode ser lida, já que se trata de "uma idéia que não pode ser pensada da forma antiga, mas sem a qual certas questões-chave não podem ser sequer pensadas" (HALL, 2000, 104).

Constituídas por meio das diferenças - estas, encontradas na região de "fronteira" - as identidades moldam-se a partir da relação com o outro, com aquilo que não é, com o exterior. Há um jogo de poder e exclusão, negação e aceitação, que vai resultar na estruturação identitária, pois

as identidades são as posições que o sujeito é obrigado a assumir, embora "sabendo", sempre, que elas são representações, que a representação é sempre construída ao longo de uma "falta", ao longo de uma divisão, a partir do lugar do Outro e que, assim, elas não 
podem, nunca, ser ajustadas (...) aos processos de sujeito que são nela investidos (HALL, 2000, 112).

Adriano Rodrigues (2000) apresenta a modernidade como o período em que o sujeito está em constante busca de libertação daquilo que possa limitar suas experiências, sua vivência, seu contato com o outro, com o diferente e o desconhecido. É uma época em que, de acordo com o estudioso, mais do que nunca, evidencia-se a necessidade do indivíduo de soltar-se das amarras do tempo e do espaço. As diferentes culturas são o primeiro alvo desta época: se a totalidade não pode ser experienciada, seria então preciso globalizar as experiências. Assim, as invenções técnicas, ao longo do tempo, refletem a peregrinação humana por ultrapassar barreiras. Pois são estas invenções os mecanismos encontrados pelos indivíduos para seguirem sempre adiante, além. Se falamos de invenção, esbarramos na televisão como meio de acessar tudo sem estar em lugar algum, apenas na sala da própria casa.

Nesta era líquida-moderna, os meios de comunicação despontam como potentes colaboradores do intrincado processo de construção identitária dos sujeitos, fabricando em grande escala modelos para projeção e identificação. Neste contexto, destacam-se as mídias audiovisuais, meio com poder suficiente para interferir no inconsciente e no imaginário social, compondo cenários em que novas identidades também flutuantes - são apresentadas e defendidas.

\section{No começo, era o cinema ...}

Antecessor da televisão, o cinema pode ser considerado matriz do imaginário coletivo brasileiro, exibindo força suficiente para suplantar a realidade existente. Por assim dizer, um filme remete a identidades ao sugerir projeções e suscitar reconhecimento. Sem contar que esta arte também nos transporta para o contato com a diversidade e a diferença, necessárias à identificação.

Integrante da indústria cultural, a cinematografia serve aos interesses de retratação do espetáculo, de forma que os temas a serem abordados precisam chamar atenção, causar impacto de alguma forma. Neste contexto, percebemos a preferência, muitas vezes, pela exibição de temáticas que estão às margens de uma ordem institucional vigente, sendo que boa parte dos filmes vai abordar o diferente. Não 
necessariamente objetivando incitar o público a refletir sobre o que se encontra alheio, mas evidenciando o que é tomado como distinto em contraste à norma social prevalecente. A dramaticidade visual e auditiva é requisito imprescindível para a eficácia e potencialização do efeito de realidade inerente à construção de representações sociais das mídias de massa audiovisuais.

Produtor e refletor de identidades que evidenciam novos sujeitos na cena cultural, o discurso cinematográfico provoca conhecimento de uma dada realidade. A série de imagens justapostas e bem editadas exibida na grande tela poderá desencadear a projeção de quem a assiste na própria história contada. Se a comunicação de massa é reprodutora da cultura, como prescreve Orlando de Miranda (1992), o cinema sob este aspecto deve ser visto. Classes subalternas e violência, por exemplo, ganham facilmente as telas brasileiras. Assim também acontece com o sexo, potencializado pela mesma ordem social que se sente ameaçada com sua repetida exposição. No intuito de se aproximar da realidade, o cinema, muitas vezes, engendra a hiper-realidade, mais próxima do espetáculo, pois

não é possível fazer uma oposição abstrata entre o espetáculo e a atividade social efetiva. O espetáculo que inverte o real é efetivamente um produto. Ao mesmo tempo, a realidade vivida é materialmente invadida pela contemplação do espetáculo e retoma em si a ordem espetacular a qual adere de forma positiva. (...) a realidade surge no espetáculo, e o espetáculo é real Essa alienação recíproca é a essência e a base da sociedade existente (DEBORD, 1997, p. 15).

\section{4 ... E veio a televisão... Trazendo as telenovelas}

União do rádio e do cinema, a televisão domesticou a imagem, que antes só existia na "telona". Com o surgimento da TV, mocinhas e vilões inicialmente apresentados na grande sala escura dos cinemas foram transportados para a telinha no aconchego dos lares. As celebridades pularam dos filmes para as novelas, passando a fazer companhia diária ao público. No Brasil, o primeiro folhetim - Sua Vida me Pertence - foi lançado na década de 50. Se anteriormente as telenovelas eram exibidas três vezes por semana, hoje vemos um bombardeio destas produções, sendo apresentados, atualmente, de seis a nove programas do gênero, por dia, na televisão brasileira. Os folhetins ultrapassaram as barreiras do lazer, pautando 
jornais e virando tema de estudos acadêmicos, por exemplo; reflexo do poder e do alcance da TV.

Roberto Amaral Vieira (1992) defende que a televisão intervém no cotidiano dos indivíduos propositadamente, a fim de construí-lo. Ao estruturar a realidade, este meio de comunicação também interferiria no inconsciente e no imaginário social. Para Vieira, a televisão é uma produção coletiva de imaginários coletivos, um meio massivo que pretende criar um grande mercado de massa, através da homogeneização de desejos e fantasias da sociedade.

O autor expõe que a televisão nos vende não apenas a moda de calças e blusas, mas também comportamentos, ideologias e sensações. Para ele, a televisão tem o poder de proporcionar alegorias que sozinho o indivíduo não tem condições de realizar. Ao comprar um objeto publicizado na TV por uma mulher sensual, por exemplo, o homem, na verdade, estaria satisfazendo o desejo de ter aquela mulher para si, e não necessariamente a mercadoria adquirida. Assim como Vieira, Orlando de Miranda (1992) também atribui à televisão importante papel na formação de mercados homogêneos: ela seria uma fonte de atualização do indivíduo com o seu tempo; ainda que seja uma modernização do e para o consumo.

Inspirando e difundindo padrões de comportamento, consumo e opinião, a televisão se revela, ainda, um liquidificador cultural, envolvendo-nos em uma densa camada de videosfera. As imagens de TV, cada vez mais em alta resolução, propõemse a levar a própria realidade para dentro das casas. Somos todos embarcados (por vontade própria, ou não?) na ilusão de que tudo que vemos na "telinha" é verdade já que programas de entretenimento, novelas e filmes, revezam-se com os jornais que se propõem a registrar a realidade -, esquecendo-nos, muitas vezes, de que televisão é mediação. Por isso, João Carlos Correia (2002) defende que é cada vez mais significativa a presença dos meios de comunicação na relação indivíduo versus sociedade, pois, de acordo com o autor, os seres humanos agem a partir dos significados que lhes são atribuídos pela mídia. Através da representação, construções identitárias adquirem sentido. E "quem tem o poder de representar tem o poder de definir e determinar a identidade" (SILVA, 2000, 91). 
A linguagem utilizada pelos media também exerce autoridade nas formações identitárias. Assim como a repetição de enunciados, idéias e conceitos, pode ser comprometedora.

Ao dizer algo sobre certas características identitárias de algum grupo cultural, achamos que estamos simplesmente descrevendo uma situação existente, um "fato" do mundo social. O que esquecemos é que aquilo que dizemos faz parte de uma rede mais ampla de atos lingǘsticos que, em seu conjunto, contribui para definir ou reforçar a identidade que supostamente apenas estamos descrevendo (SIlVA, 2000, 93).

\section{5 "Perua, piranha, minha energia é que mantém você suspensa no ar... à toa, vadia, começa uma outra história aqui na luz deste dia D..."}

A letra cantada por Caetano Veloso em uma melodia que remete ao molejo e à tropicalidade tipicamente brasileiros anuncia que Bebel está entrando em cena. Com decotes ousados, pernas a mostra e boca vermelha, a garota de programa da novela das 21 horas da Rede Globo invade nossas casas através da televisão. E fica! Por meio do bordão da personagem que será incorporado ao repertório familiar, pelo mesmo modelo de saia que será comprado, pela música "Não Enche" que será repetidamente executada no aparelho de som. A prostituta, interpretada por Camila Pitanga, é uma mulher linda, atraente e sem caráter. No início da novela, trabalhava em um bordel na cidade nordestina de Marapuã, fictícia.

Ambiciosa, individualista e com auto-estima inabalável, aliou-se a um cafetão que a levou para o Rio de Janeiro. Em terra carioca, passa a trabalhar no calçadão de Copacabana, até conhecer Olavo Novais, interpretado por Wagner Moura, com quem estabelece complexa relação permeada por atração e dinheiro. Ao tornar-se "fixa" do executivo - como a própria personagem define sua condição de prostituta que serve apenas a um cliente -, Bebel revela que seus interesses ultrapassam o vínculo empregatício, já que acaba apaixonando-se pelo patrão. A história da garota de programa está inserida em Paraíso Tropical, de Gilberto Braga e Ricardo Linhares, que estreou em março de 2007, substituindo Páginas da Vida, de Manoel Carlos. A previsão é que a produção termine em setembro de 2007.

$\mathrm{Na}$ trama, Bebel aproxima-se do perfil de vilã, pois colabora com as armações de Olavo para prejudicar os mocinhos do folhetim, Paula (Alessandra 
Negrini) e Daniel (Fábio Assunção). Poderia se pensar que a personagem de Camila Pitanga causaria repulsa no público, pois ela é conivente com o núcleo de caráter duvidoso da novela e ganha a vida exercendo uma atividade que está às margens daquelas aceitas pela sociedade. Bebel apresenta todos os requisitos para suscitar a indiferença do público receptor ante seu personagem.

No entanto, o que se percebe é uma imediata simpatia com a prostituta, de forma que, nas ruas, por exemplo, é fácil verificar mulheres que se deixam influenciar pela figura dramática de Paraíso: seja nas bolsas grandes utilizadas pela personagem na trama, ou no corte de cabelo, ou nas mini-saias que deixam as pernas à mostra. Pela interpretação da atriz, somos conduzidos à empatia que substancia uma falsa aparência do personagem. De acordo com matéria publicada na coluna Gente \& TV, do Portal Terra, a própria Camila se diz surpresa com o sucesso da personagem. "Não achava que Bebel seria adorada pelo público", declara. Fato é que a prostituta conquistou admiradores.

À medida que o público deixa-se influenciar por personagens ficionais, temos desencadeado um processo de identificação. Assim, diante de uma figura de televisão o indivíduo pode ou não se projetar, encerrando uma convergência de interesses, ou, ainda, uma partilha de desejos. Ao aproximar nossa própria imagem à de um determinado personagem, o que buscamos é nos reconhecermos como tal. Há apropriação de idéias, sentimentos, atitudes, que pode resultar em uma fusão proposital da nossa própria identidade ao do personagem.

Bebel é divertida, irreverente. Fala errado, mas quer aprender o que é certo. Não sabe portar-se em um jantar de negócios em um restaurante chique, mas contrata uma professora de boas maneiras para reverter a ignorância e obter “catiguria”. Vê na relação com Olavo não só a satisfação sexual e amorosa, como a oportunidade para mudar de vida, adquirir bens materiais até então inacessíveis e conquistar, principalmente, a dignidade enquanto mulher. Talvez, Bebel seja a imagem de tantos outros brasileiros e brasileiras que se prestam à sub vida, em atividades degradantes ou promíscuas de trabalho - não porque querem, mas porque não há outra alternativa - e que sonham um dia sair da subalternidade a que estariam condenados. Há ainda o humor e a paixão que envolvem o casal Olavo e Bebel. Os encontros e desencontros da dupla remetem às comédias românticas cuja 
fórmula já foram incansavelmente provadas e aprovadas pelo público, desde o cinema.

Deixamo-nos identificar pela autenticidade e simplicidade da personagem Bebel, além da simpatia e beleza próprias da atriz, de forma que podemos ficar na dúvida sobre onde termina Camila Pitanga e onde começa a interpretação da garota de programa. Ao receber um prêmio, no Rio de Janeiro, pelo reconhecimento do seu trabalho, Pitanga arrancou aplausos da platéia ao encarnar sua personagem em "Paraíso" - mesmo estando fora do estúdio e longe das câmeras de gravação! - e disparar o bordão "é di catiguria mermo", referindo-se à premiação, conforme nota no Portal Terra. Já em outra matéria, no site Folha On Line, Camila se apresenta como o contrário da personagem que interpreta: "Vi na Bebel uma oportunidade para me reinventar. Ela é quase meu espelho ao contrário. Tive que me desconstruir e deixar de lado minha postura alongada. Na Bebel tudo é exibido, exacerbado, quase o meu oposto. Ela chega e acontece. Eu, não...”, revelou em entrevista. Se para a atriz a personagem que interpreta é seu “espelho ao contrário", para nós, público, este mesmo espelho reflete uma imagem da qual muitos se apropriam, causando verdadeiro furor para com ator - figura dramática.

O personagem é um ser imaginário construído à semelhança do ser real, é uma figura necessária à história por mover as ações narradas. As características do personagem podem atingir a sensibilidade do espectador, provocando paixões e projeção, como acontece com Bebel. A prostituta que saiu de Marapuã para tentar a vida na capital carioca aparece, majoritariamente, em cenas caricatas, com bom grau de comicidade e que reforçam os estereótipos para este tipo de personagem, lógico, valendo-se dos artifícios do figurino, da maquiagem e da postura corporal.

\section{Conclusão}

Se para manter uma identidade é preciso reafirmá-la o tempo todo, principalmente em período de modernidade fluida, em que a efemeridade é a marca desta época, encontramos nas telenovelas o artifício necessário para manutenção dos processos de identificação. A cada novo folhetim, vemos revigorados os modelos já conhecidos, mas apresentados em nova história e interpretados por diferente ator. São rotulações sócio-culturais, fórmulas fixas, receitas prontas que não exigem 
esforço intelectual e das quais usam e abusam em produção massiva os gêneros televisivos, muitas vezes copiando o cinema, meio precursor da TV, como já abordamos anteriormente.

O que é a história de Bebel senão a mesma comédia romântica inscrita no filme Uma linda Mulher, de Garry Marshall? O romance norte americano, lançado em 1990, narra o caso vivido por uma prostituta (Julia Roberts) com um magnata (Richard Gere) que a contrata por uma semana para acompanhá-lo em eventos sociais. Neste período, a prostituta se transforma em uma elegante jovem e a relação patrão-empregada desvirtua-se em um envolvimento homem-mulher. Também nesta obra, a empatia do público com o casal é imediata, reforçando tendências e inspirando imaginário e imaginação.

Dado que os meios de comunicação massivos, em especial a televisão, são agentes significantes, fabricantes de sentidos que não apenas reproduzem a realidade, mas também a definem, encontramos na telenovela uma estrutura formal propulsora de identidades. Trabalhando com a experiência do telespectador, os folhetins apresentam personagens que ratificam valores e conceitos. Sendo a sociedade um produto humano e o homem um produto social, num cíclico processo de exteriorização - interiorização indicado por Berger (1985), a televisão tem seu papel de destaque neste sistema ao capturar idéias e imagens latentes no cenário social, apropriar-se temporariamente delas, moldá-las e devolvê-as para os indivíduos, que prontamente as re-absorvem.

Se, de um lado, temos as identidades concebidas por processos determinados pela estrutura social, de outro, encontramos a estrutura social remodelada ou mesmo modificada pelas identidades criadas. Cabe reforçar que as identidades estão em permanente construção, sujeitas aos deslizamentos e aos deslocamentos. Elas não são, portanto, unidimensionais e fixas; são múltiplas e estão em constante movimento, transformação, nomadismo e tensão, interferências estas provocadas também pelos meios de comunicação, como a televisão.

Já é passado o tempo em que família, escola e igreja dividiam, sozinhas, a responsabilidade na formação dos indivíduos. Esta tarefa também tem sido desenvolvida na atualidade pelos meios de comunicação. Desde cedo - ainda crianças 
- temos na mídia - sobretudo na televisão - um mecanismo para suprir nossas carências afetivas, espaciais e de relacionamento. É através dos meios de comunicação de massa que o indivíduo assimila considerável volume de conteúdos para construção de seu conhecimento e identidade, apesar dos meios não reivindicarem para si esta função.

\section{Referências bibliográficas}

BAUMAN, Zygmunt. Identidade: entrevista a Benedetto Vecchi. Rio de Janeiro: Jorge Zahar Editor, 2005.

BERGER, Peter L. e LUCKMANN, Thomas. A Construção Social da Realidade: Tratado de Sociologia do Conhecimento; Petrópolis: Vozes, 1985.

BHABHA, Homi K. O Local da Cultura. Belo Horizonte: Editora da UFMG, 2005.

CORREIA, João Carlos. Elementos para uma crítica da mediação moderna. Universidade da Beira, 2002. Interior. Disponível em: www.bocc.ubi.pt

Acesso em: 30 maio 2007

DEBORD, G. A sociedade do espetáculo. Comentários sobre a sociedade do espetáculo. Rio de Janeiro, Contraponto, 1997.

HALL, Stuart. Quem precisa da Identidade? In SILVA, Tomás Tadeu (org.) Identidade e Diferença: a perspectiva dos estudos culturais. Petrópolis: Vozes, 2005.

. A identidade cultural na pós-modernidade; Rio de Janeiro: DP\&A, 2006.

MIRANDA, Orlando de. Televisão, Real e Imaginário. In. Comunicação \& Política. Ano 11- no 16-1992. São Paulo: CBBLA. 1992. pp. 127-133

RODRIGUES, Adriano Duarte. Para uma genealogia do discurso da globalização da experiência. Universidade Nova de Lisboa, setembro de 2000. Disponível em: www.bocc.ubi.pt

Acesso em: 30 maio 2007

SILVA, Tomás Tadeu. A produção social da identidade e da diferença. In SILVA, Tomás Tadeu (org.) Identidade e Diferença: a perspectiva dos estudos culturais. Petrópolis: Vozes, 2005.

VIEIRA, Roberto Amaral. Televisão, Imaginário e Inconsciente. In. Comunicação \& Política. Ano 11- nº 16-1992. São Paulo: CBBLA. 1992. pp. 119-125.

WOODWARD, Kathryn. Identidade e diferença: uma introdução teórica e conceitual. In SILVA, Tomás Tadeu (org.) Identidade e Diferença: a perspectiva dos estudos culturais. Petrópolis: Vozes, 2005. 
"Bebel é quase meu oposto", diz Camila Pitanga em revista. Sete de maio de 2007. Disponível em: www.folhaonline.com.br

Acesso em: 31 julho 2007

Camila Pitanga encarna Bebel em premiação no Rio. OITO de agosto de 2007. Disponível em: www.terra.com.br Coluna Gente \& TV

Acesso em: 8 agosto 2007

"Não achava que Bebel seria adorada", diz Camila Pitanga. Três de agosto de 2007. Disponível em: www.terra.com.br Coluna Gente \& TV

Acesso em: 8 agosto 2007 